\title{
Memory in the enteric nervous system
}

\author{
J B Furness, N Clerc, W A A Kunze
}

Department of

Anatomy and Cell

Biology, and Howard

Florey Institute,

University of

Melbourne, Parkville,

Victoria 5042,

Australia

J B Furness

W A A Kunze

Laboratoire de

Neurobiologie, CNRS,

Marseille, France

N Clerc

Correspondence to: Professor J Furness,

Department of Anatomy and

Cell Biology, University of

Melbourne, Parkville,

Victoria 5042, Australia.

J.Furness@

Anatomy.Unimelb.EDU.AU

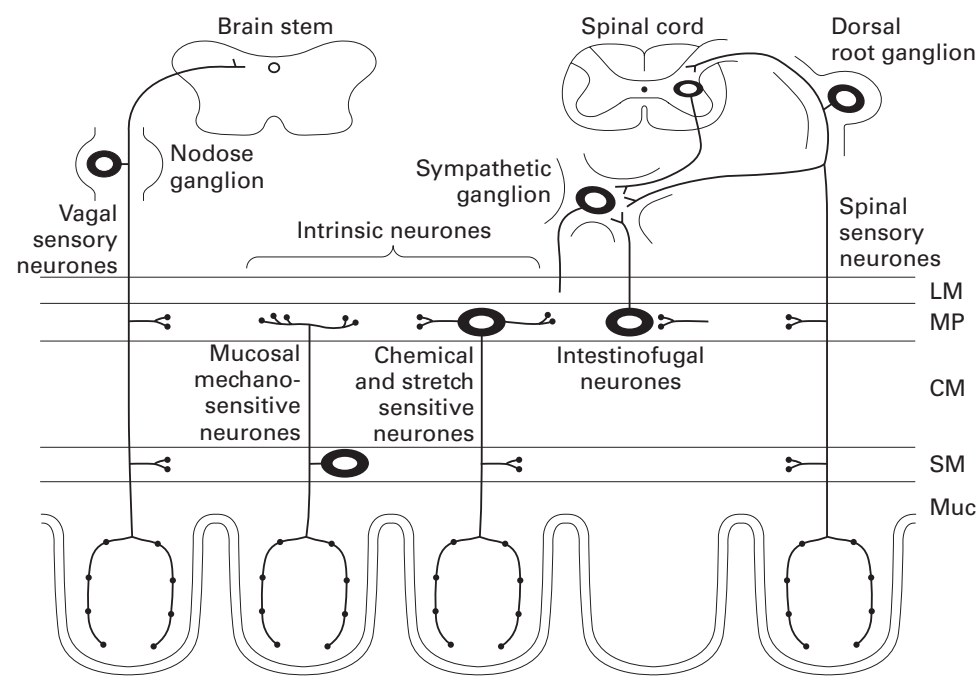

Figure 1 Representation of the types of sensory neurones of the gastrointestinal tract. Extrinsic sensory neurones: some have cell bodies in the nodose ganglion, and supply the stomach through the vagus nerves, while others have cell bodies in spinal (dorsal root) ganglia, and supply the stomach, and small and large intestines. Intrinsic sensory neurones have cell bodies in the gut wall. These have only been demonstrated recently. Another type of afferent pathway, that of intestinofugal neurones, conducts sensory information from the gut to prevertebral sympathetic ganglia. The layers of the gut wall are represented: LM, CM (longitudinal and circular muscle); MP, myenteric plexus; SM, submucosa; Muc, mucosa. enhanced if the bowel is inflamed but demonstrable inflammation is not necessary for IBS to occur. Quantitative data from human studies show that hypersensitivity includes lowering of the threshold distension for evoking pain in IBS patients. ${ }^{5}$ Hyper-reflexia in patients with IBS has been demonstrated by a decrease in threshold distension to evoke entero-enteric reflexes and by enhanced accommodation reflexes in the colon. ${ }^{6}$

There is evidence from human and animal studies that IBS-like changes can be induced by repeated stimulation. In healthy human volunteers, conditioning jejunal distension increases the perception of discomfort invoked by a test distension at an adjacent site. ${ }^{7}$ The degree to which conditioning stimuli in the sigmoid colon increase discomfort is greater in IBS than in healthy volunteers, and accommodation to distension of the sigmoid colon is also greater. ${ }^{6}$

In animals, distension of sufficient amplitude causes aversive behavioural responses and symptoms of pain. ${ }^{8}$ A change in blood pressure, which is a pseudoaffective response and is regarded as an indirect index of pain, can be recorded in both anaesthetised and unanaesthetised animals. ${ }^{2}$ Consistent with human studies, pseudoaffective responses in rats are enhanced by conditioning distension. ${ }^{9}$ As in humans with IBS or inflamed intestine, the effects of distending stimuli on gut sensitivity in animals are enhanced if there is a background of intestinal irritation. ${ }^{2}$ Even in vitro it is possible to elicit hyper-reflexia; Holzer ${ }^{10}$ showed that reflex responses to distension, which were initially attenuated by antagonising receptors for neurotransmitters, were enhanced by applying distending stimuli for five second periods at two minute intervals for 10-20 minutes.

In summary, IBS is associated with heightened sensitivity and often with hyper-reflexia, and conditions mimicking IBS can be caused by repeated distension stimuli in healthy humans and animals, and in the isolated intestine.

\section{Sustained slow postsynaptic excitation (SSPE) and cell memory}

The intestine is supplied by four systems of sensory neurones: vagal sensory neurones (cell bodies in the nodose ganglia), spinal sensory neurones (cell bodies in dorsal root ganglia), intrinsic sensory neurones (cell bodies in the gut wall), and intestinofugal neurones (cells in the intestine, terminals in sympathetic ganglia) (fig 1).

Abbreviations used in this paper: SSPE, sustained slow postsynaptic excitation; EPSPs, excitatory postsynaptic potentials; IBS, irritable bowel syndrome; LTP, long term potentiation; PKC, protein kinase C; $\mathrm{CaM}$ kinase, calcium/calmodulin dependent protein kinase. 
The intrinsic sensory neurones in which SSPE is manifested are the least studied of these. They are multipolar, with processes in the mucosa and in the enteric ganglia, and they communicate with each other through excitatory synapses and thus form networks. ${ }^{11}$ Morphologically, they are referred to as Dogiel type II neurones, and they are classified as $\mathrm{AH}$ neurones based on their electrophysiological properties. ${ }^{12}$ When sensory stimuli, such as distension stimuli used to demonstrate hyperalgesia in IBS, are applied to the intestine, the intrinsic sensory neurones are activated directly by the stimulus and indirectly through slow excitatory postsynaptic potentials (EPSPs) at their synaptic connections with each other.

Intracellular microelectrodes record slow EPSPs in Dogiel type II neurones when their presynaptic inputs are stimulated at frequencies from about 5 to $30 \mathrm{~Hz}$ in trains lasting up to about one second. The same fibre tracts, when stimulated with low frequency maintained stimulation, evoke the SSPE. The primary transmitter for the slow EPSP is a tachykinin (substance $\mathrm{P}$ ) which inhibits calcium activated conductance $\left(\mathrm{gK}_{\mathrm{Ca}}\right)$. We have recently developed methods to take patch clamp records from the Dogiel type II neurones in situ and have recorded the activity of potassium channels that may underlie the $\mathrm{gK}_{\mathrm{Ca}}{ }^{13}$ These are calcium sensitive $\mathrm{K}$ channels with conductances of about $230 \mathrm{pS}$ and are blocked by iberiotoxin. The slow EPSP is almost certainly mediated by a $G$ protein linked second messenger system. ${ }^{12}$ Firstly, slow EPSPs evoked by brief stimuli (one second or less) have a long latency (about $100 \mathrm{~ms}$ ) and a long duration (one to several minutes). Secondly, substance $\mathrm{P}$ and its analogues, which mimic the slow EPSP, cause accumulation of cyclic 3', 5' adenosine monophosphate, stimulate phosphatidylinositol turnover in enteric neurones, and increase intracellular free $\mathrm{Ca}^{2+} \cdot{ }^{14}{ }^{15}$ Thirdly, forskolin (an adenylyl cyclase activator), cyclic AMP and its analogues, and phorbol esters (protein kinase C (PKC) activators) can mimic slow EPSPs in $\mathrm{AH}$ neurones. ${ }^{16-18}$ Finally, the receptors mediating the slow EPSP in myenteric neurones have been shown to couple to $G$ proteins which are pertussis toxin insensitive. ${ }^{18}$

We decided to examine the effect of prolonged stimuli, because studies from our laboratory indicated that there was likely to be sustained activity of intrinsic sensory neurones under physiological conditions - that is, when the gut was contracting and the mucosa was exposed to nutrients. ${ }^{19-21}$

We found that extended periods (1-30 minutes) of synaptic activation of $\mathrm{AH}$ neurones in the myenteric ganglia of the guinea pig ileum at low frequency $(1 \mathrm{~Hz})$ gave rise to a slowly developing, sustained increase in excitability of the neurones associated with depolarisation and increased input resistance. The increased excitability lasted for up to 3.5 hours following the stimulus period. Successive stimulus trains (1-4 minutes) elicited successively greater increases in excitability. The neurones went through stages of excitation. Before stimulation, $500 \mathrm{~ms}$ depolarising pulses evoked $0-3$ action potentials (phasic response) and anode break action potentials were not observed. As excitability increased, more action potentials were evoked by depolarisation (the responses became tonic), anode break action potentials were observed, prolonged after hyperpolarising potentials that follow multiple action potentials were diminished and, with substantial depolarisation of the neurones, invasion by antidromic action potentials was suppressed.

The experiments imply that there is molecular memory of synaptic activity, just as there is memory of the effects of distending stimuli in vivo. The molecular memory involves changes in the regulation of $\mathrm{K}$ channels that underlie the $\mathrm{gK}_{\mathrm{Ca}}$, leading to an overall decrease in the current carried by these channels, which could be produced by reducing channel open lifetimes, by increased close times, by reducing channel current, or by reducing numbers of active channels.

A likely mechanism behind SSPE is channel phosphorylation, or phosphorylation of a channel regulator protein. Two long term changes in neurones, both involving protein phosphorylation, are similar to SSPE: long term excitation of Aplysia sensory neurones ${ }^{22}$ and long term potentiation (LTP), particularly its postsynaptic component. ${ }^{23}$ Induction and maintenance of LTP involves several kinases, at least PKC, ${ }^{24}$ calcium/calmodulin dependent protein kinase (CaM kinase), ${ }^{25}$ and the tyrosine kinase Src. ${ }^{26}$ In Aplysia sensory neurones, activation of PKC also causes long term excitability changes. ${ }^{22}$ Experiments on hippocampal CA1 neurones indicate that phosphorylation restricts the opening of $\mathrm{K}$ channels and dephosphorylation increases their opening. ${ }^{27} \mathrm{~A}$ channel phosphorylation with similar effect could lead to SSPE in enteric neurones. In support of this hypothesis, Pan and colleagues ${ }^{28}$ have shown that activation of both PKA and PKC lead to closure of $\mathrm{gK}_{\mathrm{Ca}}$ in myenteric Dogiel type II neurones. PKC also closes K channels in other cells. Pan and colleagues ${ }^{28}$ also showed that PKC $\alpha$ immunoreactivity occurs in Dogiel type II neurones. In addition, tachykinins increase $\mathrm{IP}_{3}$ levels and intracellular free calcium in enteric neurones. ${ }^{15}$ Entry of $\mathrm{Ca}^{2+}$ would have the potential to trigger phosphorylation via activation of CaM kinase.

SSPE may have some similarity in its initiation and maintenance to the postsynaptic component of LTP, which is a candidate phenomenon for laying down memory in the central nervous system. Thus SSPE may be involved in non-pathological, adaptive changes in response to altered digestive activity, and in pathological changes of neuronal excitability.

\footnotetext{
1 Mayer EA, Raybould HE. Role of visceral afferent mechanisms in functional bowel disorders. Gastroenterology 1990;99:1688-704.

2 Bueno L, Fioramonti J, Delvaux M, et al. Mediators and pharmacology of visceral sensitivity: from basic to clinical investigations. Gastroenterology 1997;112:1714-43.

3 Camilleri M, Choi M-G. Review article: irritable bowel syndrome. Aliment Pharmacol Ther 1997;11:3-15.

4 Clerc N, Furness JB, Kunze WAA, et al. Long term effects of synaptic activation at low frequency on excitability of myenteric AH neurons. Neuroscience 1999;90:279-89.
} 
5 Bradette M, Delvaux M, Staumont G, et al. Evaluation of colonic sensory thresholds in IBS patients using a barostat. Comparison with healthy subjects. Dig Dis Sci 1994:39: 449-57.

6 Munakata J, Naliboff B, Harraf F, et al. Repetitive sigmoid stimulation induces rectal hyperalgesia in patients with irritable bowel syndrome. Gastroenterology 1997;112:55-63.

7 Serra J, Azpiroz F, Malagelada J-R. Perception and reflex responses to intestinal distention in humans are modified by simultaneous or previous stimulation. Gastroenterology 1995;109:1742-49.

8 Ness TJ, Gebhart GF. Visceral pain: a review of experimental studies. Pain 1990;41:167-234.

9 McLean PG, Garcia-Villar R, Fioramonti J, et al. Effects of tachykinin receptor antagonists on the rat jejunal distension pain response. Eur f Pharmacol 1998;345:247-52.

10 Holzer P. Ascending enteric reflex: multiple transmitter systems and interactions. Am F Physiol 1989;256:G540-45.

11 Kunze WAA, Furness JB. The enteric nervous system and regulation of intestinal motility. Annu Rev Physiol 1999;61: 117-42.

12 Furness JB, Kunze WAA, Bertrand PP, et al. Intrinsic primary afferent neurons of the intestine. Prog Neurobiol 1998;54:1-18.

13 Kunze WAA, Clerc N, Furness JB, et al. The soma and neurites of primary afferent neurons in the guinea-pig intestin respond differentially to deformation. $f$ Physiol (Lond) 2000;526:375-85

14 Baidan LV, Fertel RH, Wood JD. Effects of brain-gut related peptides on cAMP levels in myenteric ganglia of guinea-pis small intestine. Eur $\mathcal{F}$ Pharmacol 1992;225:21-7.

15 Grady EF, Gamp PD, Jones E, et al. Endocytosis and recycling of neurokinin receptors in enteric neurons. Neuroscience 1996;79:1239-54

16 Nemeth PR, Palmer JM, Wood JD, et al. Effects of forskolin on electrical behaviour of myenteric neurones in guinea-pig small intestine. F Physiol (Lond) 1986;376:439-50.

17 Palmer JM, Wood JD, Zafirov DH. Elevation of adenosine 3',5'-phosphate mimics slow synaptic excitation in my3 ',5'-phosphate mimics slow synaptic excitation in my-
enteric neurones of the guinea-pig. $\mathcal{F}$ Physiol (Lond) 1986; 376:451-60.
18 Bertrand PP, Galligan JJ. Signal-transduction pathways causing slow synaptic excitation in guinea pig myenteric AH neurons. Am $\mathcal{F}$ Physiol 1995;269:G710-20.

19 Kunze WAA, Bertrand PP, Furness JB, et al. Influence of the mucosa on the excitability of myenteric neurons. Neuroscience 1997;76:619-34.

20 Kunze WAA, Furness JB, Bertrand PP, et al. Intracellular recording from myenteric neurons of the guinea-pig ileum that respond to stretch. F Physiol (Lond) 1998;506:827-42.

21 Kunze WAA, Clerc N, Bertrand PP, et al. Contractile activity in intestinal muscle evokes action potential discharge in guinea-pig myenteric neurons. f Physiol (Lond) 1999;517: 547-61.

22 Manseau F, Sossin WS, Castellucci VF. Long-term changes in excitability induced by protein kinase $\mathrm{C}$ activation in Aplysia sensory neurons. F Neurophysiol 1998;79:1210-18.

23 Blitzer RD, Connor JH, Brown GP, et al. Gating of CaMKII by cAMP-regulated protein phosphatase activity during LTP. Science 1998;280:1940-43.

24 Wang J-H, Feng D-P. Postsynaptic protein kinase C essential to induction and maintenance of long-term potentiation in the hippocampal CA1 region. Proc Natl Acad Sci USA 1992;89:2576-80.

25 Otmakhov N, Griffith LC, Lisman JE. Postsynaptic inhibitors of calcium/calmodulin-dependent protein kinase type II block induction but not maintenance of pairinginduced long-term potentiation. F Neurosci 1997;17:535765.

26 Lu YM, Roder JC, Davidow J, et al. Src activation in the induction of long-term potentiation in CA1 hippocampal neurons. Science 1998;279:1363-67.

27 Pedarzani P, Krause M, Haug T, et al. Modulation of the $\mathrm{Ca}^{2+}$-activated $\mathrm{K}^{+}$current $\mathrm{SI}_{\mathrm{AHP}}$ by a phosphatase-kinase balance under basal conditions in rat CA1 pyramidal neurons. F Neurophysiol 1998;79:3252-6.

28 Pan $\mathrm{H}$, Wang $\mathrm{H}-\mathrm{Y}$, Friedman E, et al. Mediation by protein kinases $\mathrm{C}$ and $\mathrm{A}$ of $\mathrm{G}_{0}$-linked slow responses of enteric neurons to 5-HT. $\mathcal{F}$ Neurosci 1997;17:1011-24. 